\title{
Endothelial Progenitor Cell Migration-Enhancing Factors in the Secretome of Placental-Derived Mesenchymal Stem Cells
}

\author{
Witchayaporn Kamprom, , ${ }^{1,2}$ Pakpoom Kheolamai, ${ }^{2,3,4}$ Yaowalak U-Pratya, ${ }^{2,5}$ \\ Aungkura Supokawej, ${ }^{6}$ Methichit Wattanapanitch, ${ }^{2}$ Chuti Laowtammathron, ${ }^{2}$ \\ Sittiruk Roytrakul, ${ }^{7}$ and Surapol Issaragrisil ${ }^{2,5}$ \\ ${ }^{1}$ Department of Immunology, Faculty of Medicine Siriraj Hospital, Mahidol University, Bangkok 10700, Thailand \\ ${ }^{2}$ Siriraj Center of Excellence for Stem Cell Research, Faculty of Medicine Siriraj Hospital, Mahidol University, Bangkok 10700, Thailand \\ ${ }^{3}$ Division of Cell Biology, Faculty of Medicine, Thammasat University, Pathumthani 12120, Thailand \\ ${ }^{4}$ Center of Excellence in Stem Cell Research, Faculty of Medicine, Thammasat University, Pathumthani 12120, Thailand \\ ${ }^{5}$ Division of Hematology, Department of Medicine, Faculty of Medicine Siriraj Hospital, Mahidol University, Bangkok 10700, Thailand \\ ${ }^{6}$ Department of Clinical Microscopy, Faculty of Medical Technology, Mahidol University, Bangkok 73170, Thailand \\ ${ }^{7}$ Proteomics Research Laboratory, Genome Institute, National Science and Technology Development Agency, \\ Pathumthani 12120, Thailand \\ Correspondence should be addressed to Surapol Issaragrisil; surapolsi@gmail.com
}

Received 16 July 2015; Revised 13 October 2015; Accepted 25 October 2015

Academic Editor: Leonard M. Eisenberg

Copyright (C) 2016 Witchayaporn Kamprom et al. This is an open access article distributed under the Creative Commons Attribution License, which permits unrestricted use, distribution, and reproduction in any medium, provided the original work is properly cited.

\begin{abstract}
Therapeutic potentials of mesenchymal stem cells (MSCs) depend largely on their ability to secrete cytokines or factors that modulate immune response, enhance cell survival, and induce neovascularization in the target tissues. We studied the secretome profile of gestational tissue-derived MSCs and their effects on functions of endothelial progenitor cells (EPCs), another angiogenic cell type that plays an important role during the neovascularization. MSCs derived from placental tissues (PL-MSCs) significantly enhanced EPC migration while BM-MSCs, which are the standard source of MSCs for various clinical applications, did not. By using protein fractionation and mass spectrometry analysis, we identified several novel candidates for EPC migration enhancing factor in PL-MSCs secretome that could be used to enhance neovascularization in the injured/ischemic tissues. We recommend that the strategy developed in our study could be used to systematically identify therapeutically useful molecules in the secretomes of other MSC sources for the clinical applications.
\end{abstract}

\section{Introduction}

Mesenchymal stem cells (MSCs) are multipotent stem/progenitor cells which can differentiate to several mesodermal derivatives and possess an ability to secrete factors involved in neovascularization and immunomodulation $[1,2]$. Previous studies demonstrated that MSCs could ameliorate the pathology associated with ischemic heart disease, ischemic stroke, and peripheral vascular disease by releasing several critical factors that increase cell survival, provide an appropriate microenvironment for repairing damaged tissue, and induce neovascularization [3-5].
For several decades, neovascularization is believed to be accomplished by proliferation of mature endothelial cells residing in the local vessels through the process of angiogenesis [6]. However, recent studies have demonstrated that other angiogenic cells called endothelial progenitor cells (EPCs) also play an important role during the formation of new vessels through the process of vasculogenesis [7-9]. Vasculogenesis involves migration of EPCs from blood circulation into injured/ischemic tissues where they proliferate and generate new vessels de novo. The effects of factors released from bone-marrow-derived MSCs (BM-MSCs), which are the standard source of MSCs for clinical applications, on the 
functional properties of mature endothelial cells have been previously reported [10-12]; however the effects of MSCderived factors on EPC functions have yet to be characterized.

Apart from BM-MSCs which require highly invasive procedure for their isolation, MSCs can be easily obtained in large quantity from several gestational tissues using noninvasive procedure [13, 14]. Gestational tissues have currently been considered more suitable sources of MSCs for clinical applications. However, recent studies showed that MSCs derived from distinct sources might produce distinct combination of factors that exert different effects on target cells $[15,16]$. Therefore, characterization of the secretome of distinct MSC sources is critical for selecting suitable MSCs for specific applications. The secretomes of BM-MSCs and adipose-derived MSCs were recently studied [17-19]; however the secretomes of gestational tissue-derived MSCs are still poorly characterized.

The present study aimed to investigate the effect of factors released from placental-derived MSCs (PL-MSCs) on EPC migration, which is a critical step of vasculogenesis, using an in vitro migration assay. Moreover, the candidate EPC migration inducing factors presented in PL-MSCs secretome were identified using protein fractionation and mass spectrometry analysis.

\section{Materials and Methods}

2.1. Isolation and Culture of PL-MSCs. This study was approved by the Siriraj Institutional Review Board, Faculty of Medicine Siriraj Hospital, Mahidol University, which was in accordance with the Declaration of Helsinki, the Belmont Report, CIOMS Guidelines, and ICH-GCP. Placental tissues and umbilical cord blood were obtained from healthy newborns after receiving signed informed consents from their mothers. Placental tissues were minced into small pieces and incubated with $0.25 \%$ trypsin-EDTA at $37^{\circ} \mathrm{C}$ for 30 minutes in shaking water bath. After incubation, the digested tissues were plated into $25 \mathrm{~cm}^{2}$ tissue culture flask containing complete medium (Dulbecco's Modified Eagle's Medium (DMEM; GIBCO, Invitrogen Corporation, USA) supplemented with $10 \%(\mathrm{v} / \mathrm{v})$ Fetal Bovine Serum (FBS; Lonza, USA), $100 \mathrm{U} / \mathrm{mL}$ penicillin (General Drug House Co., Ltd., Thailand), and $100 \mu \mathrm{g} / \mathrm{mL}$ streptomycin (General Drug House Co., Ltd., Thailand)). The cultures were maintained at $37^{\circ} \mathrm{C}$ in a humidified atmosphere containing $5 \% \mathrm{CO}_{2}$ and the medium was replaced every 3 days throughout the entire culture period.

2.2. Isolation and Culture of BM-MSCs. Bone marrow samples $(n=5)$ were obtained from healthy donors by bone marrow aspiration after giving a written informed consent. Bone marrow mononuclear cells (BM-MNCs) were isolated by density gradient centrifugation ( $400 \mathrm{~g}$ for 20 minutes at $20^{\circ} \mathrm{C}$ ). The BM-MNCs were then resuspended in complete DMEM medium, plated into $25 \mathrm{~cm}^{2}$ flask at a density of $2 \times 10^{5}$ cells $/ \mathrm{cm}^{2}$, and cultured at $37^{\circ} \mathrm{C}$ in a humidified atmosphere containing $5 \% \mathrm{CO}_{2}$. After 48 -hour culture, the nonadherent cells were removed and fresh medium was added. Cultures were maintained at $37^{\circ} \mathrm{C}$ in a humidified atmosphere containing $5 \% \mathrm{CO}_{2}$ and medium was replaced every 3 days throughout the entire culture period.

2.3. Immunophenotyping of PL-MSCs and BM-MSCs. The 3rd-5th passages of MSCs were harvested by trypsinization and incubated with $10 \mu \mathrm{L}$ of the following mouse anti-human antibodies: anti-CD34-FITC (BD Pharmingen, USA), antiCD45-PE (BD Pharmingen, USA), anti-CD90-FITC (AbD Serotec, USA), anti-CD73-PE (BD Pharmingen, USA), and anti-CD105-PE (Miltenyi Biotec, Germany) for 30 minutes at $4^{\circ} \mathrm{C}$ in the dark. After incubation, cells were washed twice with PBS and fixed with $300 \mu \mathrm{L} 1 \%$ (v/v) paraformaldehyde. The expression profiles of cell surface markers were then determined by FACSCalibur flow cytometry (Becton Dickinson, USA) using CellQuest software. Cells labeled with FITC-conjugated mouse IgG1 (eBioscience, USA) and PE-conjugated mouse IgG1 (eBioscience, USA) served as negative controls.

\subsection{Osteogenic and Adipogenic Differentiation of PL-MSCs} and BM-MSCs. For adipogenic differentiation, $5 \times 10^{4} \mathrm{MSCs}$ (3rd-5th passages) were cultured in NH AdipoDiff Medium (Miltenyi Biotec, Germany). The medium was replaced every 3 days according to the manufacturer's instructions. After culture for 4 weeks, cells were stained with $0.5 \%$ (w/v) Oil Red O (Sigma Aldrich, USA) in isopropanol for 20 minutes at room temperature and were observed under phase-contrast microscope (Olympus, Japan). For osteogenic differentiation, $5 \times 10^{4}$ MSCs (3rd-5th passages) were cultured in $\mathrm{NH}$ OsteoDiff Medium (Miltenyi Biotec, Germany). The medium was replaced every 3 days according to the manufacturer's instructions. After culture for 3 weeks, cells were stained with $40 \mathrm{mM}$ Alizarin Red S (Sigma Aldrich, USA) for 20 minutes at room temperature and were observed under phase-contrast microscope (Olympus, Japan).

2.5. Culture and Characterization of EPCs from Umbilical Cord Blood. Twenty milliliters of heparinized umbilical cord blood was collected for EPC isolation. Mononuclear cell populations from umbilical cord blood were isolated using IsoPrep (Robbins Scientific Corporation, USA) density gradient centrifugation, washed twice with Phosphate Buffer Saline (PBS; GIBCO, Invitrogen Corporation, USA), resuspended in endothelial cell growth medium (endothelial basal medium-2 (LONZA, Germany), supplemented with EGM-2 single aliquots (LONZA, Germany) containing 2\% (v/v) FBS, $5 \mu \mathrm{g} / \mathrm{mL}$ epidermal growth factor, $200 \mu \mathrm{g} / \mathrm{mL}$ hydrocortisone, $0.5 \mu \mathrm{g} / \mathrm{mL}$ vascular endothelial growth factor, $10 \mu \mathrm{g} / \mathrm{mL}$ basic fibroblast growth factor, $20 \mu \mathrm{g} / \mathrm{mL}$ long R3 insulin-like growth factor 1 , and $1 \mathrm{mg} / \mathrm{mL}$ ascorbic acid), and plated into an individual well of 6-well plate coated with $10 \mu \mathrm{g} / \mathrm{mL}$ human fibronectin (Amersham Biosciences, USA) at a density of $1 \times 10^{6}$ cells/well. After culture for 3 days, the nonadherent cells were removed and fresh medium was added. The cultures were maintained at $37^{\circ} \mathrm{C}$ in a humidified atmosphere containing $5 \% \mathrm{CO}_{2}$ and the medium was replaced every 3 days throughout the entire culture period. 
Cells were characterized for EPC surface markers by incubating with the following mouse anti-human antibodies: anti-CD34-FITC (R\&D Systems, USA), anti-VEGFR2-PE (R\&D Systems, USA), anti-CD31-PE (BioLegend, USA), and anti-vWF-FITC (R\&D Systems, USA) for 15 minutes at $4^{\circ} \mathrm{C}$ in the dark. After incubation, cells were washed twice with PBS and fixed with $2 \%(\mathrm{v} / \mathrm{v})$ paraformaldehyde in PBS. Flow cytometry was performed using FACSCalibur flow cytometer (Becton Dickinson, USA) and CellQuest software. Cells labeled with FITC-conjugated mouse IgG1 (eBioscience, USA) and PE-conjugated mouse IgG1 (eBioscience, USA) served as negative controls.

To further examine the characteristics of EPCs, an in vitro vessel formation assay was performed. Briefly, $100 \mu \mathrm{L}$ Matrigel (BD Bioscience, USA) was added to an individual well of 4-well plate (Corning, USA) and allowed to polymerization at $37^{\circ} \mathrm{C}$ for 1 hour. At this stage, $1 \times 10^{5}$ EPCs were resuspended in endothelial cell growth medium, plated into an individual well of Matrigel-coated 4-well plate, and cultured at $37^{\circ} \mathrm{C}$ in a humidified atmosphere containing $5 \% \mathrm{CO}_{2}$ for 24 hours. At the end of culture, the extent of capillary-like structure was observed by phase-contrast microscopy (Olympus, Japan).

\subsection{Preparation and Fractionation of PL-MSCs Conditioned} Medium. $7 \times 10^{5}$ PL-MSCs (3rd-5th passages) were plated into $75 \mathrm{~cm}^{2}$ flask containing complete medium and incubated in a humidified atmosphere containing $5 \% \mathrm{CO}_{2}$ for 24 hours. After incubation, cells were washed twice with $5 \mathrm{~mL}$ sterile PBS and incubated with $15 \mathrm{~mL}$ serum-free medium (SFM) (DMEM supplemented with $100 \mathrm{U} / \mathrm{mL}$ penicillin and $100 \mu \mathrm{g} / \mathrm{mL}$ streptomycin) for further 24 hours. After incubation, the PL-MSCs conditioned medium was collected, $15 \mathrm{~mL}$ fresh SFM was added, and cells were incubated for further 24 hours. After incubation, the conditioned medium was collected and pooled with the earlier collected PL-MSCs conditioned medium. The pooled PL-MSCs conditioned medium was then centrifuged at $400 \mathrm{~g}$ for 10 minutes at $4^{\circ} \mathrm{C}$ and filtered through $0.45 \mu \mathrm{m}$ syringe filter (Corning, USA). The filtered conditioned medium was fractionated into 5 distinct fractions according to the molecular weight of their protein composition using various ultraspin columns with molecular weight cut-off (MWCO) at $100 \mathrm{kDa}$ (Pall Corporation, USA), $50 \mathrm{kDa}$ (Merck, Germany), $30 \mathrm{kDa}$ (Pall Corporation, USA), and $10 \mathrm{kDa}$ (Pall Corporation, USA) according to the manufacturer's instructions. To fractionate PL-MSCs conditioned medium, the medium was transferred to $100 \mathrm{kDa}$ ultraspin columns and centrifuged at $4700 \mathrm{~g}$ for 15 minutes at $4^{\circ} \mathrm{C}$. After centrifugation, the fraction of PLMSCs conditioned medium retained in the column was collected while the flow-through was transferred to the $50 \mathrm{kDa}$ ultraspin columns for further centrifugation. By repeating this procedure with the $30 \mathrm{kDa}$ and $10 \mathrm{kDa}$ columns, the PL-MSCs conditioned medium was successfully fractionated into $100 \mathrm{kDa}, 50 \mathrm{kDa}, 30 \mathrm{kDa}, 10 \mathrm{kDa}$, and less than $10 \mathrm{kDa}$ fractions.

2.7. Preparation of the $100 \mathrm{kDa}$ Subfraction of PL-MSCs Secretome by Reverse-Phase Chromatography. The $100 \mathrm{kDa}$ fraction of PL-MSCs conditioned medium was further fractionated into several subfractions according to the hydrophobicity of their protein composition by reverse-phase chromatography. Firstly, Sep-Pak C18 Vac cartridge (Waters Associates, USA) was washed twice with $35 \mathrm{~mL} 100 \%$ acetonitrile (ACN) followed by equilibration with $35 \mathrm{~mL}$ $0.1 \%$ trifluoroacetic acid (TFA). The solutions were allowed to drain at the rate of $1 \mathrm{~mL} / \mathrm{min}$ by connecting to Perista pump AC2110 (ATTO, Japan). After equilibration, the $100 \mathrm{kDa}$ fraction was transferred into the preequilibrated Sep-Pak C18 cartridge followed by the addition of $35 \mathrm{~mL} 0.1 \%$ TFA. The fluid was allowed to drain and the hydrophobic proteins presented in the $100 \mathrm{kDa}$ fraction were sequentially eluted from the column by increasing $\mathrm{ACN}$ concentration from $10 \%$ to $100 \%$. The eluted solutions were collected and separated into distinct subfractions and the amount of proteins presented in each subfraction were determined by measuring an absorbance at $280 \mathrm{~nm}$ and $220 \mathrm{~nm}$ by nanodrop 2000 spectrophotometer (Thermo Scientific, USA). Finally, acetonitrile and TFA remaining in each subfraction were eliminated by vacuum centrifugation.

2.8. In Vitro Migration Assay. To investigate the paracrine effect of BM-MSCs and PL-MSCs on EPC migration, EPCs were cocultured with MSCs through $8 \mu \mathrm{m}$ pore size transwell (Corning, USA) as shown in Figure 3(a). Briefly, $5 \times 10^{4}$ MSCs were plated into the lower chamber of transwell containing $600 \mu \mathrm{L}$ complete DMEM medium. The culture was then maintained at $37^{\circ} \mathrm{C}$ in a humidified atmosphere containing $5 \% \mathrm{CO}_{2}$ for 24 hours to allow cell attachment. After 24-hour incubation, the medium was replaced with $600 \mu \mathrm{L}$ DMEM supplemented with $2 \%(\mathrm{v} / \mathrm{v}) \mathrm{FBS}, 100 \mathrm{U} / \mathrm{mL}$ penicillin, and $100 \mu \mathrm{g} / \mathrm{mL}$ streptomycin and cells were then cultured for further 24 hours. On the following day, $4 \times 10^{4}$ EPCs were seeded into the upper chamber of transwell inserts which already contained MSCs in the lower chamber. The coculture was maintained at $37^{\circ} \mathrm{C}$ in a humidified atmosphere containing $5 \% \mathrm{CO}_{2}$ for further 6 hours. At the end of culture, the number of EPCs which migrate to the other side of transwell inserts were determined by hematoxylin staining. The EPCs cultured in transwells whose lower chamber contained cellfree DMEM medium served as controls. Data were presented as mean \pm SEM of three independent experiments.

The effect of fractionated PL-MSCs conditioned medium on EPC migration was studied using an in vitro migration assay. $4 \times 10^{4}$ cells EPCs were seeded into the upper chamber of transwell inserts (Corning, USA) while the lower chamber was added with either $100 \mathrm{kDa}, 50 \mathrm{kDa}, 30 \mathrm{kDa}, 10 \mathrm{kDa}$, or less than $10 \mathrm{kDa}$ fraction of the conditioned medium. Cells were then incubated at $37^{\circ} \mathrm{C}$ in a humidified atmosphere containing 5\% $\mathrm{CO}_{2}$ for further 6 hours. The migratory capacity of EPCs toward each fractionated PL-MSCs conditioned medium was determined by hematoxylin staining. EPCs cultured in transwells whose lower chamber contained serum-free medium (SFM) served as negative controls while EPCs cultured in transwells whose lower chamber contained unfractionated PL-MSCs conditioned medium served as positive controls. The effect of each $100 \mathrm{kDa}$ subfraction on 
EPC migration was also determined by the same procedure as described above. In this case, EPCs cultured in transwells whose lower chamber contained unfractionated $100 \mathrm{kDa}$ medium served as controls.

2.9. Mass Spectrometry Analysis and Protein Identification. Mass spectrometry analysis was performed at the National Center for Genetic Engineering and Biotechnology (BIOTEC), Thailand. The proteins presented in each PLMSCs conditioned medium fraction were digested by incubation with trypsin and analyzed by ESI ion trap mass spectrometry. Identification and quantification of each protein was determined by DeCyder MS differential analysis software 2.0 (GE Healthcare, USA) and MASCOT search engine software (Matrix Science, UK) based on NCBInr human protein databases. The identified proteins were then categorized into nonsecretory, classical secretory, and nonclassical secretory proteins by SignalP and SecretomeP software (Center for Biological Sequence Analysis (CBS), Denmark). Finally, the secretory proteins were further categorized by PANTHER and UniProt software into separated groups according to their functions.

2.10. Statistical Analysis. Data were presented as mean \pm standard error of the mean (SEM). The Mann-Whitney test and nonparametric Kruskal-Wallis test were used to assess the significance of differences between observed data. $P<0.05$ was considered to be statistically significant.

\section{Results}

3.1. Characteristics of PL-MSCs, BM-MSCs, and CB-EPCs. Placenta-derived mesenchymal stem cells (PL-MSCs) and bone-marrow-derived mesenchymal stem cells (BM-MSCs) established in this study displayed fibroblast-like morphology (Figure 1(a)), could differentiate to adipocytes and osteocytes as demonstrated by Oil Red O (Figure 1(b)) and Alizarin Red $\mathrm{S}$ staining (Figure 1(c)), and exhibited typical MSC surface markers (positive for CD73, CD90, and CD105 and negative for hematopoietic markers CD34 and CD45) (Figure 1(d)). Umbilical cord blood-derived endothelial progenitor cells (CB-EPCs) established in this study displayed cobblestonelike morphology, which is typical for EPCs (Figure 2(a)), formed capillary-like structures on Matrigel (Figure 2(b)), and expressed typical EPC surface markers CD34, VEGFR2, vWF, and CD31 (Figure 2(c)).

3.2. Effect of MSC-Derived Secretory Factors on EPC Migration. To investigate the effect of MSC-derived soluble factors on EPC migration, EPCs were cocultured with BMMSCs and PL-MSCs using the transwell culture system (Figure 3(a)). The numbers of EPCs that migrate toward BM-MSCs and PL-MSCs were determined after 6 hours of coculture. The soluble factors derived from PL-MSCs significantly enhanced EPC migration compared to controls $(109.7 \pm 12.0$ cells/field versus $39.2 \pm 10.1$ cells/field, $P=$ 0.002) while BM-MSCs failed to induce EPC migration (37.4 \pm 7.2 cells/field versus $39.2 \pm 10.1$ cells/field of controls)
(Figures 3(b) and 3(c)), suggesting that only soluble factors which were uniquely released from PL-MSCs could enhance EPC migration.

3.3. Effect of Fractionated PL-MSCs Conditioned Medium on EPC Migration. To identify PL-MSC-derived factors which are able to induce EPC migration, PL-MSCs conditioned medium was fractionated into 5 distinct fractions according to the molecular weight of their protein compositions. The effect of each PL-MSCs conditioned medium fraction on EPC migration was then determined by in vitro migration assay (Figure 4(a)). Only the unfractionated and $100 \mathrm{kDa}$ fraction of PL-MSCs conditioned medium could significantly enhance EPC migration compared to negative controls $(44.0 \pm 15.6$ versus $1.7 \pm 1.2$ cells/field, $P=0.01$ for the unfractionated PL-MSC conditioned medium, and 108.2 \pm 7.9 versus $1.7 \pm 1.2$ cells/field, $P=0.01$ for the $100 \mathrm{kDa}$ fraction) while the other fractions including $50 \mathrm{kDa}$ fraction $(21.1 \pm$ 3.5 versus $1.7 \pm 1.2$ cells/field), $30 \mathrm{kDa}$ fraction $(4.4 \pm 3.9$ versus $1.7 \pm 1.2$ cells/field), $10 \mathrm{kDa}$ fraction $(3.1 \pm 2.1$ versus $1.7 \pm 1.2$ cells/field), and less than $10 \mathrm{kDa}$ fraction $(3.2 \pm 1.6$ versus $1.7 \pm 1.2$ cells/field) did not enhance EPC migration (Figures 4(b) and 4(c)). The number of migrated EPCs induced by the $100 \mathrm{kDa}$ fraction, which were approximately 2.5-fold higher than those induced by the unfractionated PLMSCs conditioned medium (Figure 4(c)), clearly indicates that the PL-MSC-derived factors which are able to induce EPC migration were fractionated into the $100 \mathrm{kDa}$ fraction.

\subsection{Effects of the $100 \mathrm{kDa}$ Subfractions of PL-MSCs Secretome} on EPC Migration. To identify EPC migratory enhancing factors presented in the $100 \mathrm{kDa}$ of PL-MSCs conditioned medium, proteins presented in the $100 \mathrm{kDa}$ fraction of PLMSCs conditioned medium were further fractionated into 11 subfractions according to their hydrophobicity (see Supplementary Figure 1 of the Supplementary Material available online at http://dx.doi.org/10.1155/2016/2514326). The effect of each $100 \mathrm{kDa}$ subfraction on EPC migration was then determined by in vitro migration assay. Only subfractions 5 and 6 of the $100 \mathrm{kDa}$ fraction could enhance EPC migration (32.4 cells/field and 35.32 cells/field, resp.) whereas the rest of the subfractions did not (Figures 5(a) and 5(b)). The numbers of migrated EPCs induced by subfractions 5 (32.4 cells/field) and 6 (35.32 cells/field) were 2-fold lower than those induced by the $100 \mathrm{kDa}$ fraction (64.12 cells/field), indicating that subfraction 5 and subfraction 6 of the $100 \mathrm{kDa}$ fraction contained EPC migratory enhancing factors.

\subsection{Identification of Candidate EPC Migratory Enhancing} Factors in PL-MSCs Secretome. EPC migratory enhancing factors presented in PL-MSCs secretome were identified by mass spectrometry. Proteins presented in the $100 \mathrm{kDa}$ fraction, subfraction 5, and subfraction 6 were identified by DeCyder differential analysis software based on their signal intensities. The $100 \mathrm{kDa}$ fraction contained 251 proteins while subfraction 5 and subfraction 6 contained 258 and 239 proteins, respectively (Figure 6(a)). The proteins presented in $100 \mathrm{kDa}$ fraction which were subsequently fractionated into 

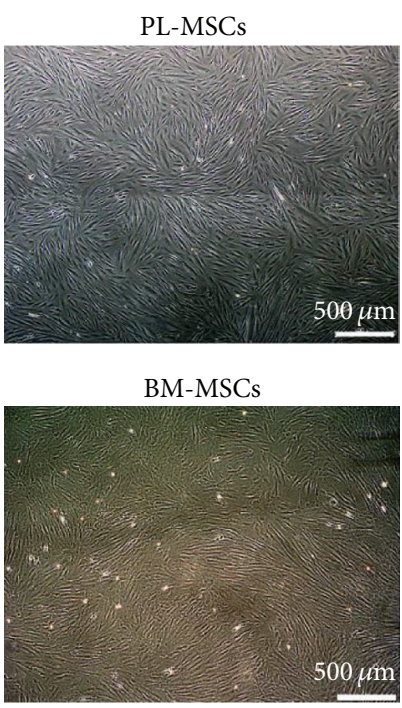

(a)
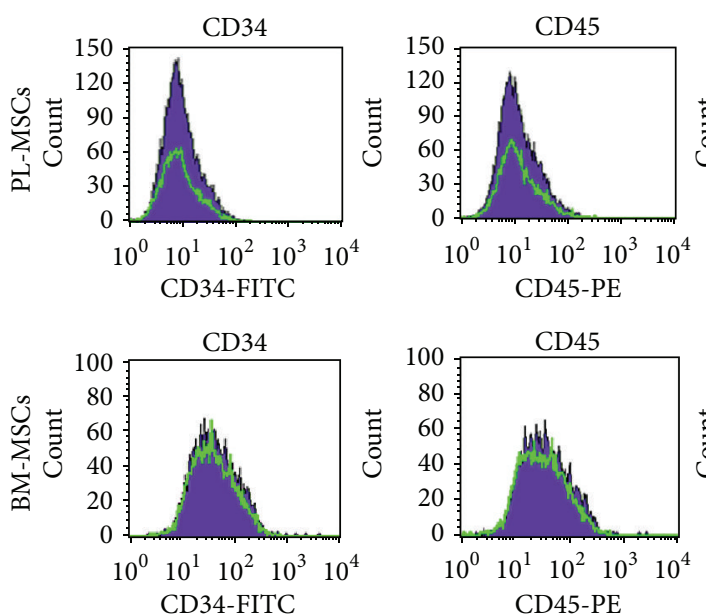

(d)
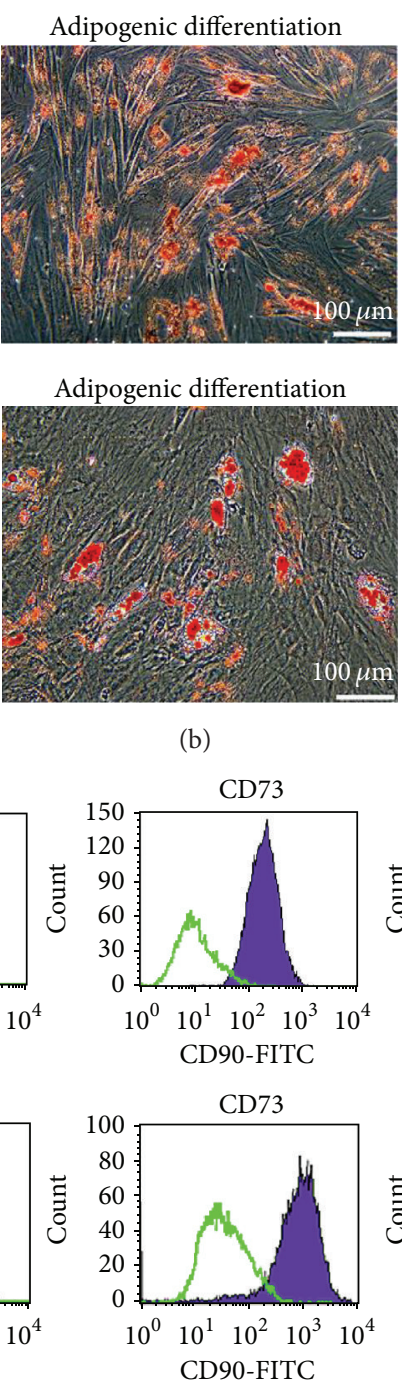

(b)

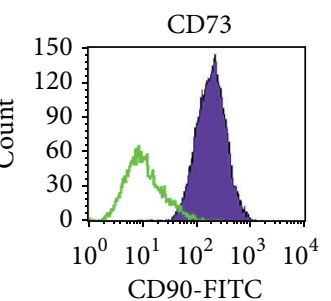

-FITC
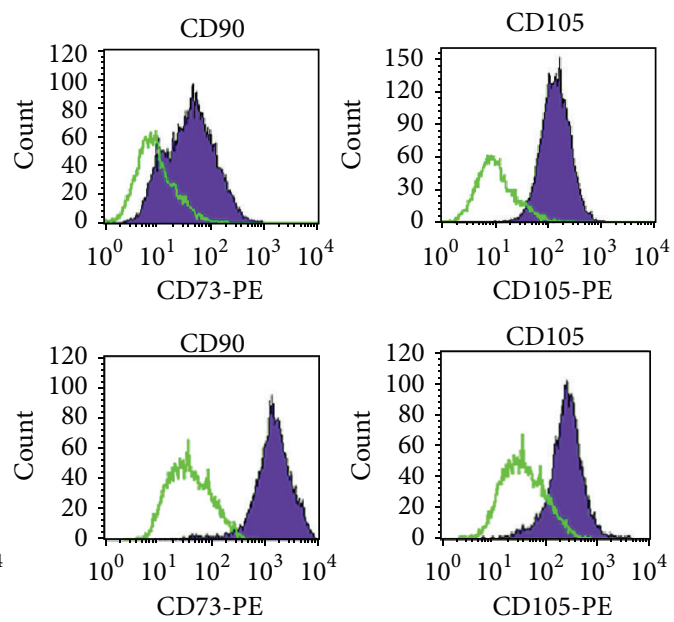

FIgURE 1: Characteristics of PL-MSCs and BM-MSCs. (a) Fibroblast-like morphology of PL-MSCs and BM-MSCs (scale bar $=500 \mu \mathrm{m}$ ). (b) Adipogenic differentiation of PL-MSCs and BM-MSCs as demonstrated by Oil Red O staining (scale bar $=100 \mu \mathrm{m})$. (c) Osteogenic differentiation of PL-MSCs and BM-MSCs as demonstrated by Alizarin Red S staining (scale bar $=500 \mu \mathrm{m}$ ). (d) Immunophenotype of PLMSCs and BM-MSCs as determined by flow cytometry.

subfraction 5 and/or subfraction 6 were considered to be possible candidates for EPC migratory inducing factor. There were 183 proteins in all 3 fractions. 38 proteins were presented in $100 \mathrm{kDa}$ fraction and subfraction 5 and 18 proteins were presented in $100 \mathrm{kDa}$ fraction and subfraction 6 (Figure 6(a)).

Those $239(183+38+18)$ candidate proteins were further categorized into nonsecreted protein, classically secreted protein, and nonclassically secreted protein by SignalP 4.1 and SecretomeP 2.0 software. Of 239 proteins, 131 were nonsecreted proteins, 85 were nonclassically secreted proteins, and 23 were classically secreted proteins (Figure 6(b)). To identify EPC migratory enhancing factors, 162 nonsecreted and unidentified proteins were excluded while 77 nonclassically and classically secreted proteins (Supplementary Table 1) were further categorized into various groups based on their functions, such as extracellular matrix, receptors, proteinase, cytoskeletal proteins, cytokine, and enzymes (Figure 6(c)) by PANTHER classification and UniProt software.

Among those 77 secreted proteins, we further identified the possible candidates for EPC migratory enhancing factor using the following criteria: (A) the candidates must be classical secretory proteins, (B) the candidates must not belong to an apoptotic pathway, and $(C)$ the candidates must be previously reported to be involved in cell migration and/or neovascularization process. According to those criteria, 12 proteins were considered to be possible candidates for EPC migratory enhancing factors. These proteins include astrotactin-1, ADAMTS1, plexin-B1, heparin cofactor 2, Sushi domain-containing protein 2, plasminogen (Angiostatin), PILR alpha-associated neural protein, lymphocyte antigen 


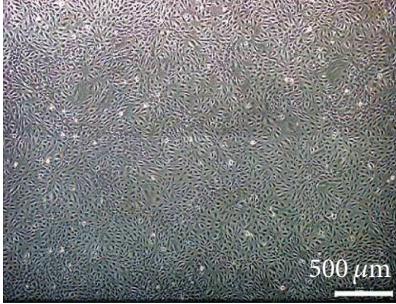

(a)
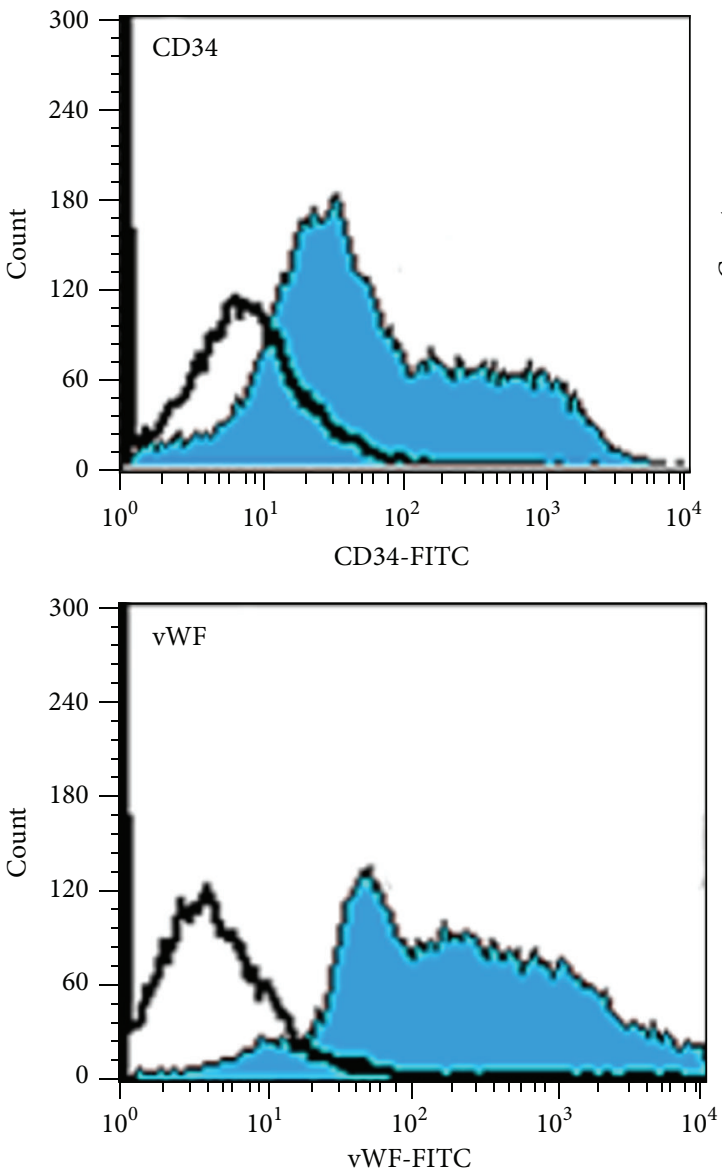

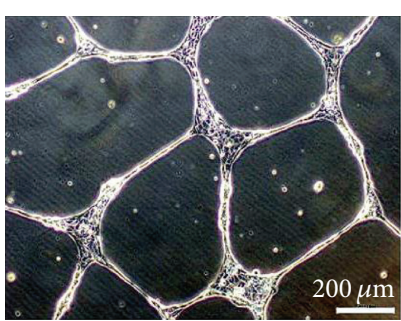

(b)
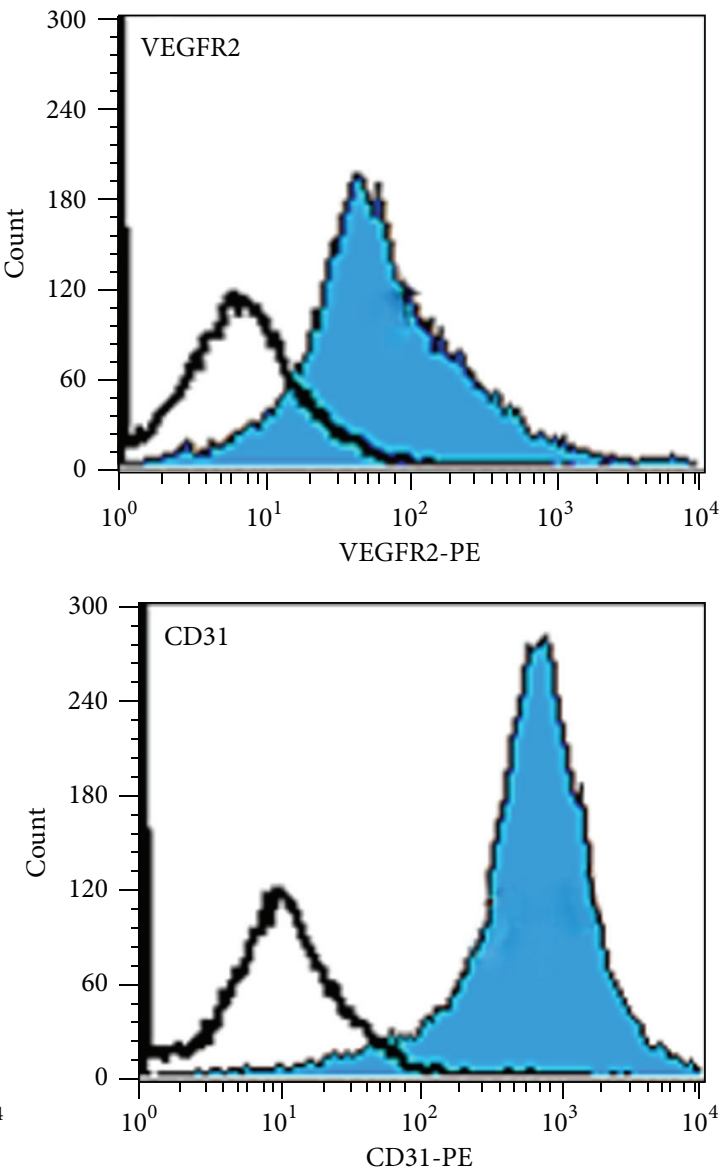

(c)

FIGURE 2: Characteristic of endothelial progenitor cells (EPCs). (a) Cobblestone-like morphology of EPC colony appeared after 7 days of culture (scale bar $=500 \mu \mathrm{m}$ ). (b) Capillary-like structures derived from EPCs after culture on Matrigel for 24 hours $(\mathrm{scale}$ bar $=200 \mu \mathrm{m})$. $(\mathrm{c})$ Immunophenotype of EPCs as determined by flow cytometry.

75, type IV collagen, laminin, semaphorin receptor, and small inducible cytokine subfamily E, member 1 (endothelial monocyte-activating) (Table 1).

\section{Discussion}

MSCs have been regarded as promising sources for cell therapy. The therapeutic potentials of MSCs depend on their multilineage differentiation capacity and their ability to secrete broad range of cytokines and growth factors which modulate immune response, enhance cell survival, and induce neovascularization in the target tissues [20]. The secretome profiles of BM-MSCs and adipose tissuederived MSCs (AD-MSCs) have been analyzed $[18,21]$ and were shown to contain several proangiogenic factors including VEGF, bFGF, ANGPT1, IL6, MCP-1, and SDF1 [22]. Furthermore, a previous study also demonstrated that factors released from mouse BM-MSCs enhanced proliferation, survival, migration, and vessel-forming capacity of mature endothelial cells [23]. However, the secretome profile of gestational tissue-derived MSCs and their effects on the 


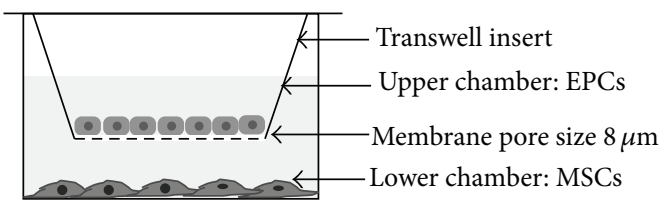

(a)
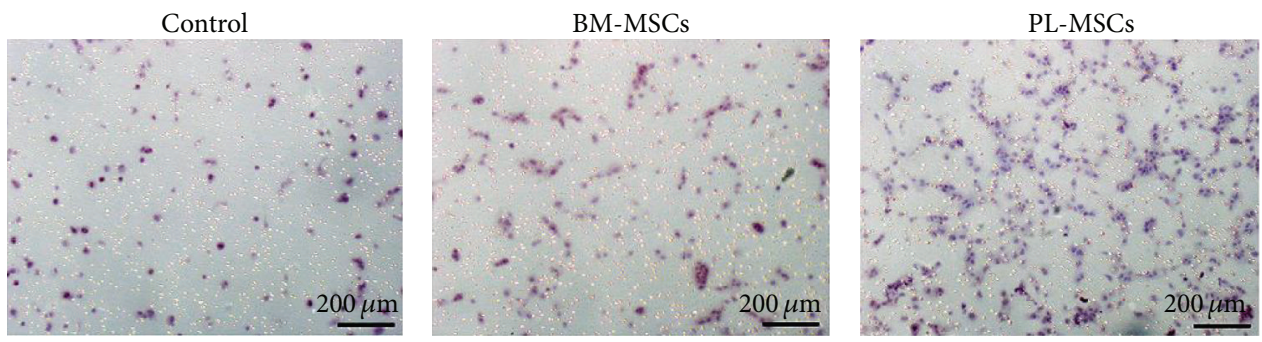

(b)

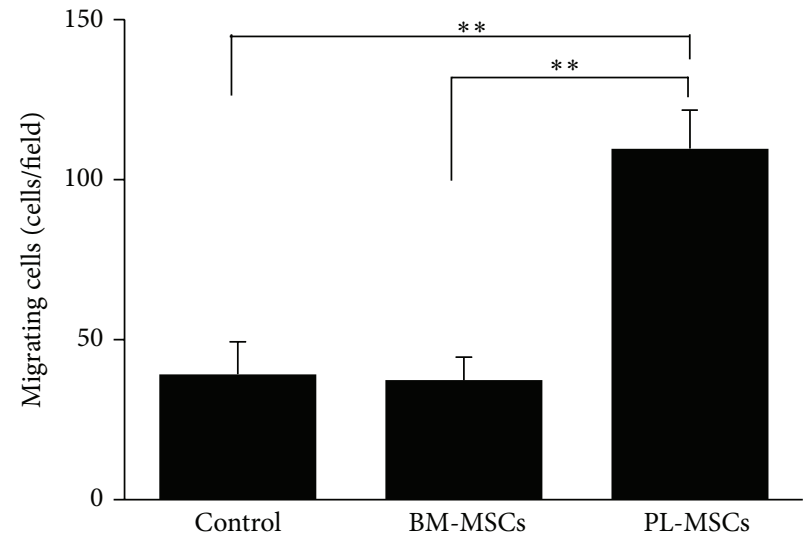

(c)

Figure 3: Effects of soluble factors released from BM-MSCs and PL-MSCs on EPC migration. (a) Diagram of the transwell culture system for an in vitro migration assay. (b) Hematoxylin stained EPCs which migrated to the other side of transwell membrane in response to soluble factors released from BM-MSCs and PL-MSCs. EPCs cultured in transwells containing serum-free medium (SFM) serve as negative controls. (c) Number of EPCs which migrated in response to soluble factors released from BM-MSCs and PL-MSCs. Data were presented as mean \pm SEM of three independent experiments. Mann-Whitney $U$ test was used to assess the significance of differences between observed data. ${ }^{* *} P<0.01$.

functions of EPCs which play an important role during neovascularization is still poorly characterized.

We showed that PL-MSCs derived soluble factors significantly enhanced EPC migration and their migration enhancing effect was even greater than that of BM-MSCs. Despite the fact that there are several reports describing the positive effect of BM-MSCs on the function of mature endothelial cells (ECs), there have been no previous reports on the effects of BM-MSCs on the properties of endothelial progenitor cells (EPCs). Previous studies demonstrated the enhancing effect of BM-MSCs on EC migration; however our results showed that BM-MSCs did not affect EPC migration. It is possible that the $\mathrm{EC}$ and $\mathrm{EPC}$ migration requires different proangiogenic factors. Previous studies showed that VEGF released from BM-MSCs and chorionic blood vessel-derived MSCs (bv-MSCs) enhances EC migration [24-27]. In our study, a subfraction of secretome from PL-MSCs supposed to contain VEGF did not enhance EPC migration in the transwell culture system.
To further identify EPC migration enhancing factors presented in PL-MSCs secretome, PL-MSCs conditioned medium was separated into several distinct fractions according to the molecular weight and hydrophobicity of their protein components. EPC migration enhancing factors were enriched in subfractions 5 and 6 of the $100 \mathrm{kDa}$ fraction of PLMSCs secretome. Mass spectrometry analysis revealed that PL-MSCs secreted hundreds of different proteins through classical and nonclassical secretory pathway. The nonsecretory intracellular proteins leaked from dead cells during culture were also identified in the PL-MSCs conditioned medium and excluded from subsequent analysis [28].

Using this strategy, 77 PL-MSC-derived secretory proteins presented in subfraction 5 and/or 6 of the $100 \mathrm{kDa}$ fraction of PL-MSCs secretome were identified. Among those secreted proteins, 12 proteins previously reported to be involved in cell migration and/or neovascularization process were identified as candidates for EPC migration enhancing factors. Those include (A) laminin and collagen IV which 


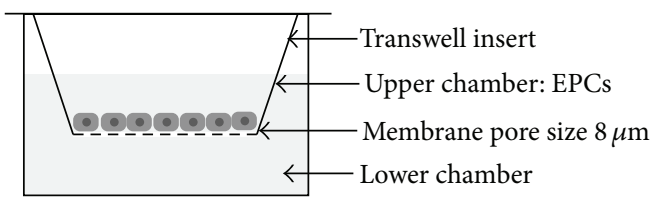

(a)

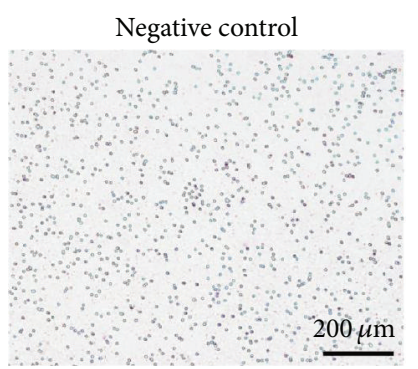

$50 \mathrm{kDa}-\mathrm{CM}$

Positive control

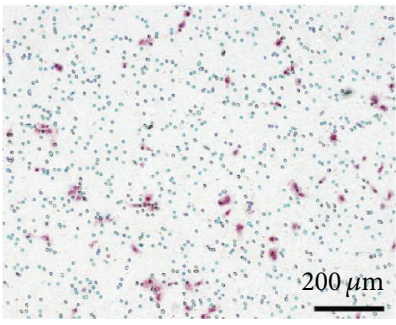

$30 \mathrm{kDa}-\mathrm{CM}$
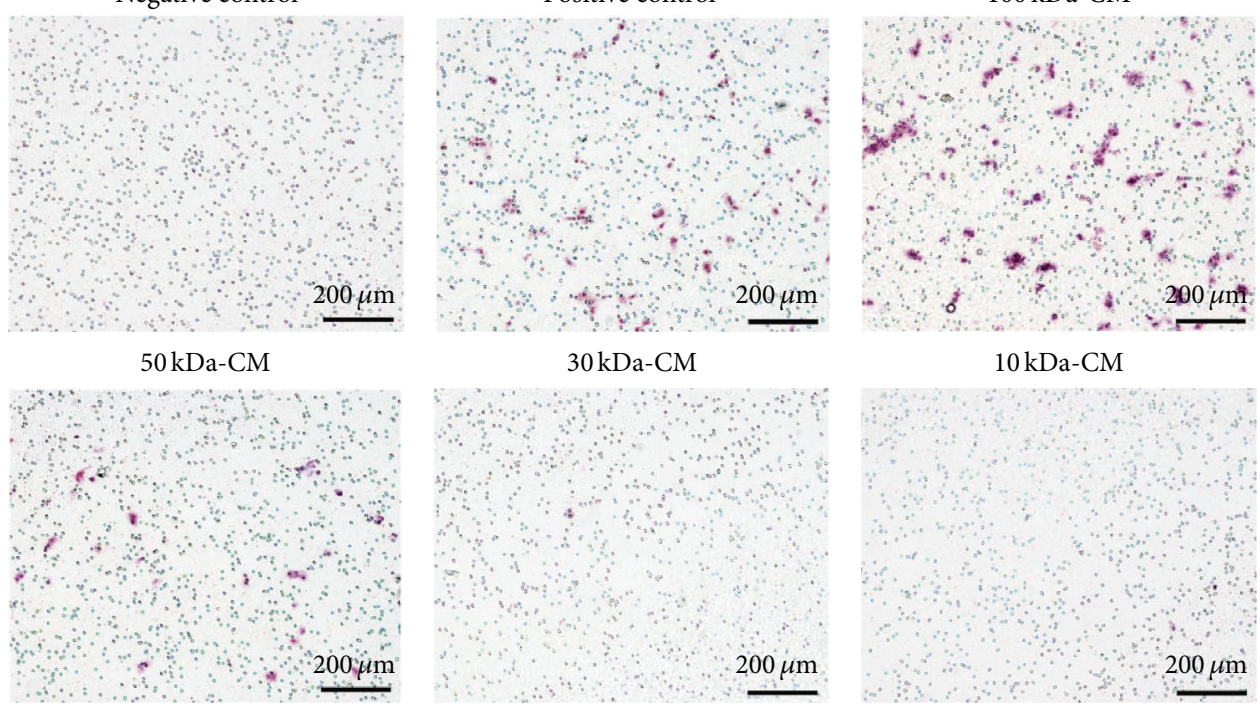

$10 \mathrm{kDa}-\mathrm{CM}$

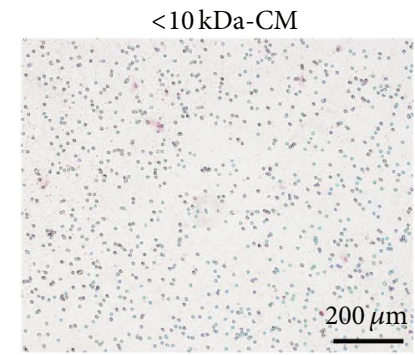

(b)

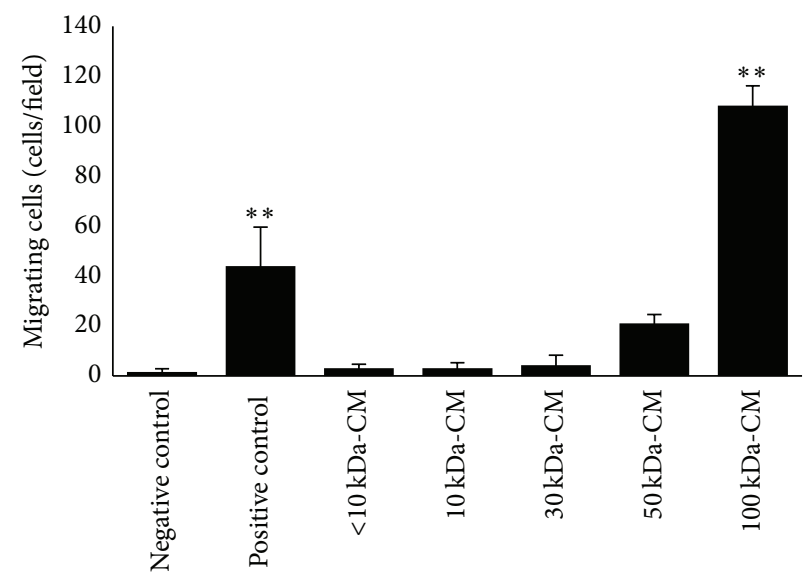

(c)

FIGURE 4: Effect of PL-MSCs conditioned medium fractions on EPC migration. (a) Diagram of the transwell culture system for an in vitro migration assay. (b) Hematoxylin stained EPCs which migrated to the other side of membrane in response to soluble factors presented in the $100 \mathrm{kDa}, 50 \mathrm{kDa}, 30 \mathrm{kDa}, 10 \mathrm{kDa}$, and less than $10 \mathrm{kDa}$ fractions of the PL-MSCs conditioned medium (scale bar $=200 \mu \mathrm{m})$. (c) Numbers of EPCs which migrated in response to soluble factors presented in the $100 \mathrm{kDa}, 50 \mathrm{kDa}, 30 \mathrm{kDa}, 10 \mathrm{kDa}$, and less than $10 \mathrm{kDa}$ fractions of PL-MSCs conditioned medium. EPCs cultured in transwells whose lower chamber contained serum-free medium (SFM) served as negative controls while EPCs cultured in transwells whose lower chamber contained unfractionated PL-MSCs conditioned medium served as positive controls. Data were presented as mean \pm SEM of three independent experiments. Nonparametric Kruskal-Wallis test was used to assess the significance of differences between observed data. ${ }^{* *} P<0.01$ versus negative control. 

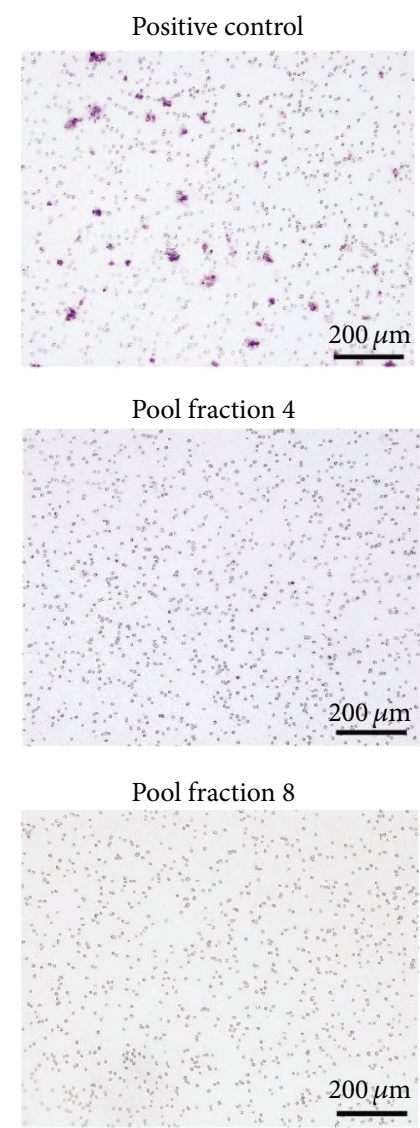

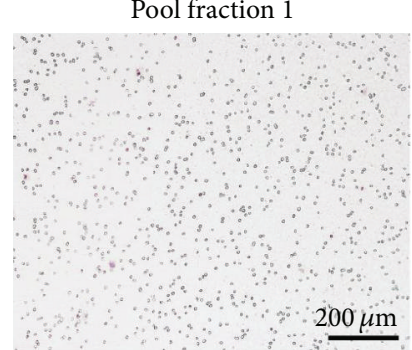

Pool fraction 5

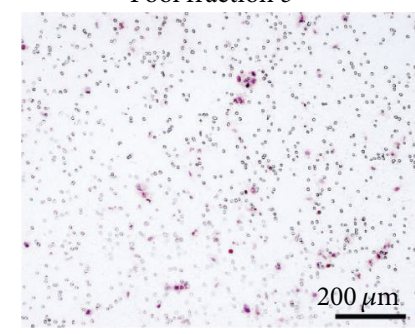

Pool fraction 9

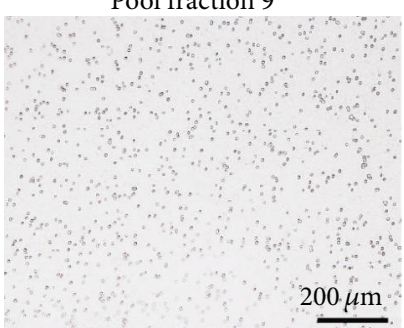

Pool fraction 2
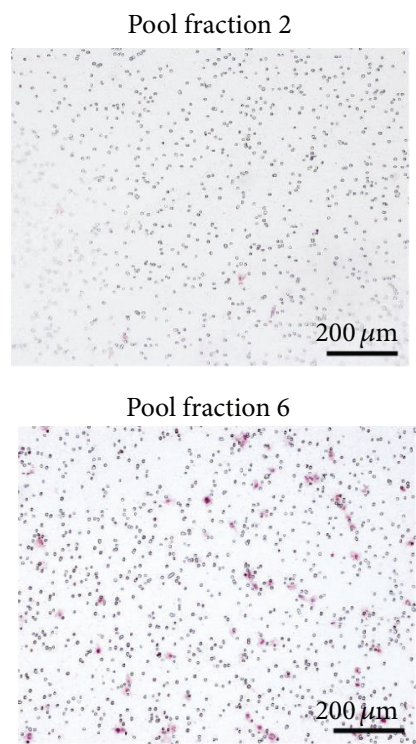

Pool fraction 10

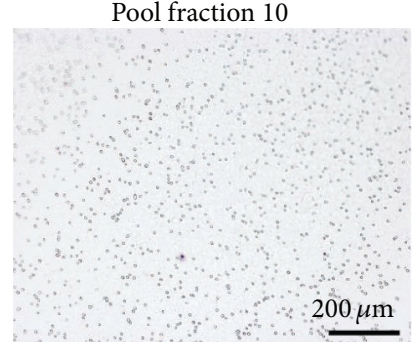

Pool fraction 3

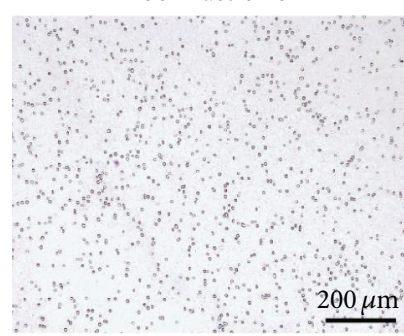

Pool fraction 7

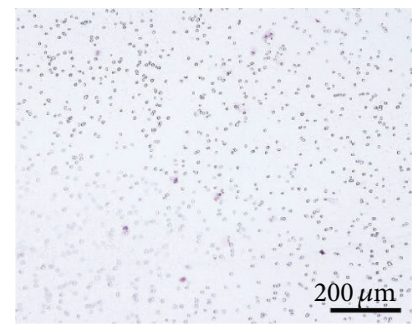

Pool fraction 11

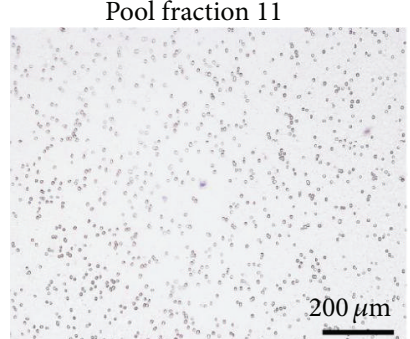

(a)

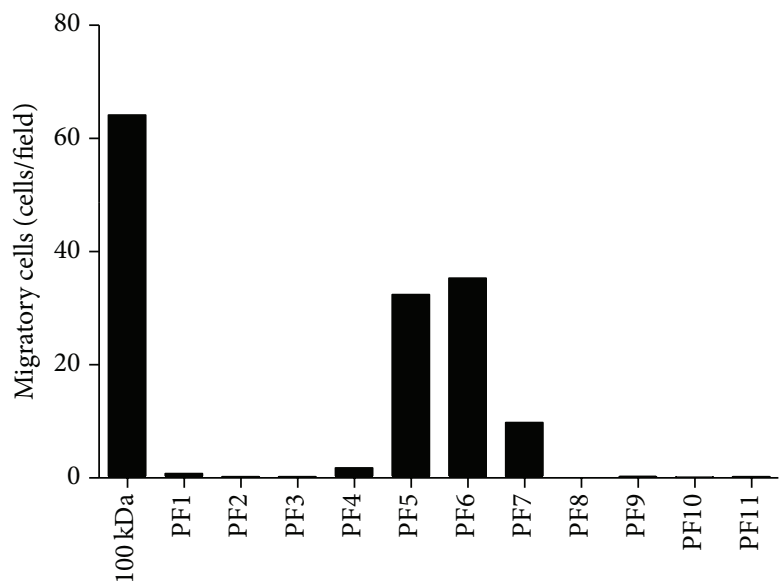

(b)

FIGURE 5: Effect of the $100 \mathrm{kDa}$ subfractions on EPC migration. (a) Hematoxylin stained EPCs which migrated to the other side of membrane in response to soluble factors presented in 11 distinct subfractions $(\mathrm{PF})$ of the $100 \mathrm{kDa}$ fraction of PL-MSCs conditioned medium $(\mathrm{scale}$ bar $=$ $200 \mu \mathrm{m}$ ). (b) Number of EPCs which migrated in response to soluble factors presented in 11 distinct subfractions of the $100 \mathrm{kDa}$ fraction of PL-MSCs conditioned medium.

are extracellular matrix proteins involved in cell adhesion and migration of endothelial and tumor cells [29-31], (B) a disintegrin and metalloproteinase with thrombospondin motif (ADAMTS1), a member of metalloprotease family, which plays important roles in ECM degradation and cell migration; a previous study demonstrated that ADAMTS1 enhanced proliferation and migration of endothelial cells under hypoxic condition [32], (C) a protein semaphorin and its receptor plexin-B1 which possesses proangiogenic activity [33], (D) serpin peptidase inhibitor, clade D, member 1 (SERPIND1) which promotes angiogenesis by enhancing proliferation, migration, and vessel-forming capacity of 


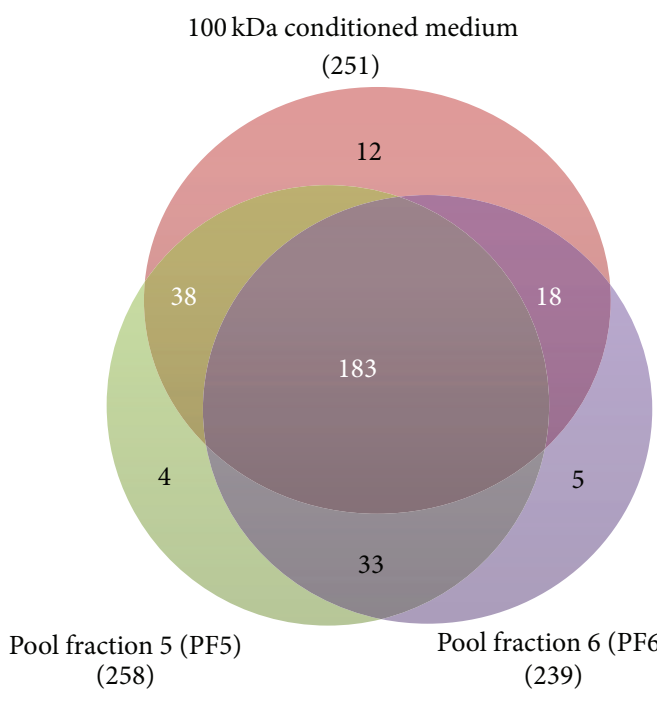

(a)
Nonclassically secreted proteins (85)

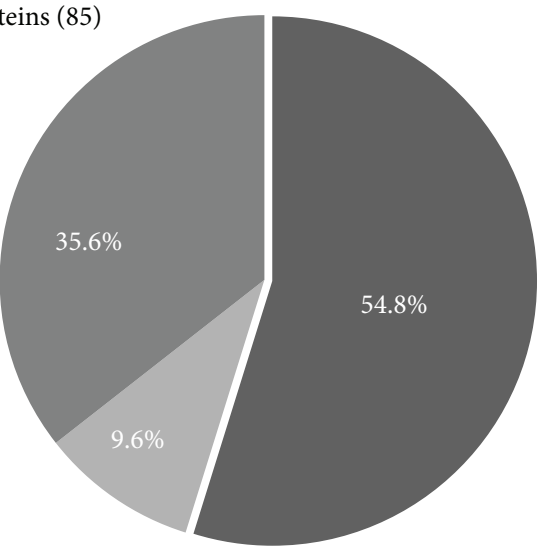

Classically secreted proteins

(23)
Nonsecreted proteins

(131)

(b)

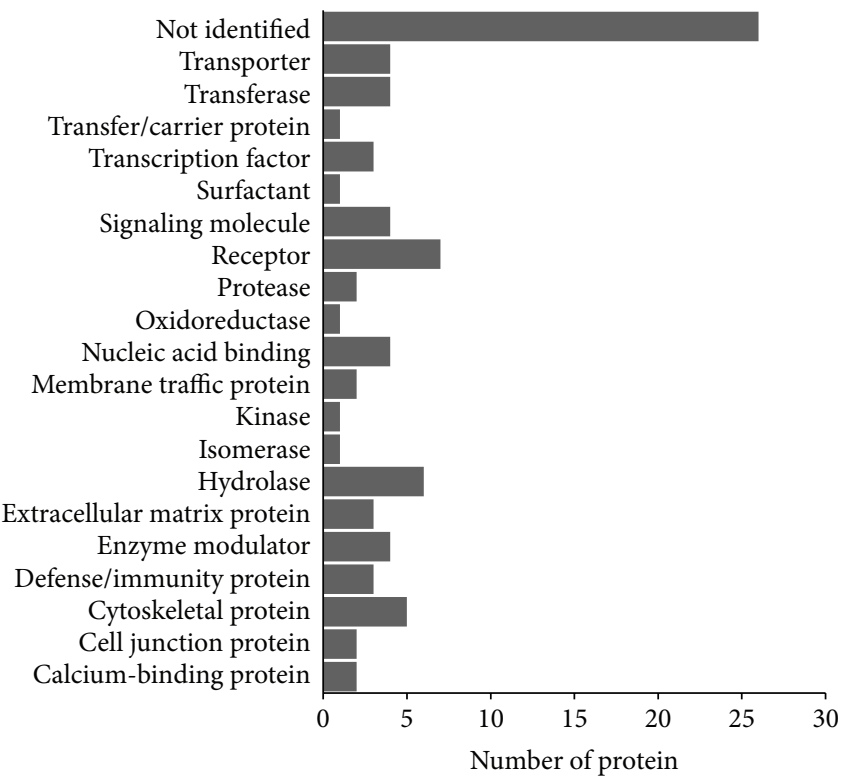

(c)

Figure 6: Characterization of PL-MSCs secretome. (a) Venn diagram illustrates the proteins presented in $100 \mathrm{kDa}$ fraction of PL-MSCs conditioned medium as well as those presented in subfraction 5 and subfraction 6 of the $100 \mathrm{kDa}$ fraction. Number of proteins presented in the $100 \mathrm{kDa}$ fraction which were subsequently fractionated into subfraction 5 and/or subfraction 6 (labeled with white color) were regarded as candidate proteins. (b) Pie chart illustrates 239 candidate proteins which were further categorized into nonsecreted protein, classically secreted protein, and nonclassically secreted protein, by SignalP 4.1 and SecretomeP 2.0 software. (c) Graph demonstrates functions of 77 secretory proteins based on PANTHER classification and UniProt.

endothelial cells [34], and (E) angiostatin and endothelial monocyte-activating polypeptide II which exerts its EPC migration inducing effect through its receptor CXCR3 [35, 36].

The positive effect of PL-MSCs on EPC migration described in our study is in agreement with a previous report demonstrating that several gestational tissue-derived MSCs, including chorionic blood vessel-derived MSCs (bv-MSCs), amniotic membrane-derived MSCs (hAMCs), and umbilical cordderived MSCs (UC-MSCs) released proangiogenic factors which enhance migration and vessel-forming capacity of mature endothelial cell $[24,27,37]$. We have identified several novel proteins in addition to the well-known proangiogenic factors described in previous studies using ELISA array to identify MSC secretome [24, 27, 37]. The mass spectrometry analysis used in our study could discover the complete protein composition of PL-MSCs secretome in an unbias manner and with higher sensitivity while an ELISA array can only determine the amount of limited number of well-known proangiogenic factors presented in PL-MSCs. Our study is 
TABLE 1: List of EPC migratory enhancing factor candidates in PL-MSCs secretome.

\begin{tabular}{|c|c|c|c|c|}
\hline Protein name & $\begin{array}{l}\text { Accession } \\
\text { number }\end{array}$ & $\begin{array}{l}\text { Secretory pathway } \\
\text { prediction }\end{array}$ & Biological function & $\begin{array}{c}\text { UniProtKB } \\
\text { accession } \\
\text { number }\end{array}$ \\
\hline Astrotactin-1 & gi|46488923 & Classical & $\begin{array}{c}\text { Neuron migration and neuronal } \\
\text { adhesion }\end{array}$ & O14525 \\
\hline ADAMTS1 & gi|119631213 & Classical & $\begin{array}{l}\text { Metalloprotease involve in } \\
\text { extracellular matrix remodeling }\end{array}$ & Q9UHI8 \\
\hline Plexin-B1 & gi|6010211 & Classical & $\begin{array}{l}\text { Axon guidance and cell } \\
\text { migration }\end{array}$ & O43157 \\
\hline Heparin cofactor 2 (SERPIND1) & gi|23273330 & Classical & $\begin{array}{l}\text { Chemotactic activity for } \\
\text { monocyte and neutrophil }\end{array}$ & P05546 \\
\hline $\begin{array}{l}\text { Sushi domain-containing protein } \\
2\end{array}$ & gi|10092665 & Classical & Immune response & Q9UGT4 \\
\hline Plasminogen (angiostatin) & gi|38051823 & Classical & $\begin{array}{c}\text { Blood coagulation } \\
\text { Angiogenesis inhibitor }\end{array}$ & P00747 \\
\hline $\begin{array}{l}\text { PILR alpha-associated neural } \\
\text { protein }\end{array}$ & gi|24308547 & Classical & Immune regulation & Q8IYJ0 \\
\hline Lymphocyte antigen 75 & gi|32307817 & Classical & $\begin{array}{l}\text { Inflammation and immune } \\
\text { process }\end{array}$ & O60449 \\
\hline Type IV collagen & gi|15991848 & Classical & $\begin{array}{c}\text { Extracellular matrix/cell } \\
\text { adhesion }\end{array}$ & Q14031 \\
\hline Laminin & gi|119613854 & Classical & Cell adhesion and cell migration & Q13751 \\
\hline Semaphorin receptor & gi|6010211 & Classical & $\begin{array}{l}\text { Axon guidance and cell } \\
\text { migration }\end{array}$ & O43157 \\
\hline $\begin{array}{l}\text { Small inducible cytokine } \\
\text { subfamily E, member } 1 \\
\text { (endothelial } \\
\text { monocyte-activating) }\end{array}$ & gi|119626608 & Nonclassical & Angiogenesis & Q12904 \\
\hline
\end{tabular}

also the first report that describes the effects of PL-MSCs secretome on the migration capacity of EPCs.

\section{Conclusion}

We herein report for the first time that PL-MSCs secreted unique combination of factors which enhance EPC migration and their effect is greater than that of BM-MSCs. We also identified several novel candidates for EPC migration enhancing factor in PL-MSCs secretome which have been reported to enhance proliferation, migration, and vesselforming capacity of mature endothelial cells. The factors discovered in this study could be used to implement the therapeutic effect of MSCs by enhancing neovascularization in the injured/ischemic tissues. Moreover, the strategy developed in our study could be used to systematically identify other therapeutically useful molecules in the secretomes of other MSC sources. However, the therapeutic effects of EPC migration enhancing factors identified in this study should be further confirmed by in vitro and in vivo studies before use in the clinical applications.

\section{Conflict of Interests}

The authors declare no conflict of interests. There were no commercial organizations or funding bodies associated with data collection and analysis, or with this study paper.

\section{Authors' Contribution}

Witchayaporn Kamprom performed the experiments and drafted the paper. Pakpoom Kheolamai designed the experiments, analyzed the data, supervised the study, wrote and finalized the paper. Aungkura Supokawej, Yaowalak UPratya, Methichit Wattanapanitch, Chuti Laowtammathron, and Sittiruk Roytrakul analyzed the data. Surapol Issaragrisil conceived and supervised the study and wrote and finalized the paper. All authors read and approved the final paper.

\section{Acknowledgments}

This research project was funded by grants from Thailand Research Fund (Grant no. RTA 488-0007), the Commission on Higher Education (Grant no. CHE-RES-RG-49). S. Issaragrisil is a Senior Research Scholar of Thailand Research Fund. Witchayaporn Kamprom was supported by the Royal Golden Jubilee Ph.D. Program of the Thailand Research Fund.

\section{References}

[1] L. da Silva Meirelles, A. M. Fontes, D. T. Covas, and A. I. Caplan, "Mechanisms involved in the therapeutic properties of mesenchymal stem cells," Cytokine and Growth Factor Reviews, vol. 20, no. 5-6, pp. 419-427, 2009. 
[2] M. Gnecchi, Z. Zhang, A. Ni, and V. J. Dzau, "Paracrine mechanisms in adult stem cell signaling and therapy," Circulation Research, vol. 103, no. 11, pp. 1204-1219, 2008.

[3] S. H. Ranganath, O. Levy, M. S. Inamdar, and J. M. Karp, "Harnessing the mesenchymal stem cell secretome for the treatment of cardiovascular disease," Cell Stem Cell, vol. 10, no. 3, pp. 244-258, 2012.

[4] W. Huang, B. Lv, H. Zeng et al., "Paracrine factors secreted by MSCs promote astrocyte survival associated with GFAP downregulation after ischemic stroke via p38 MAPK and JNK," Journal of Cellular Physiology, vol. 230, no. 10, pp. 2461-2475, 2015.

[5] R. Katare, F. Riu, J. Rowlinson et al., "Perivascular delivery of encapsulated mesenchymal stem cells improves postischemic angiogenesis via paracrine activation of VEGF-A," Arteriosclerosis, Thrombosis, and Vascular Biology, vol. 33, no. 8, pp. 18721880, 2013.

[6] P. Carmeliet and R. K. Jain, "Molecular mechanisms and clinical applications of angiogenesis," Nature, vol. 473, no. 7347, pp. 298307, 2011.

[7] J. M. Melero-Martin, Z. A. Khan, A. Picard, X. Wu, S. Paruchuri, and J. Bischoff, "In vivo vasculogenic potential of human bloodderived endothelial progenitor cells," Blood, vol. 109, no. 11, pp. 4761-4768, 2007.

[8] P. Au, L. M. Daheron, D. G. Duda et al., "Differential in vivo potential of endothelial progenitor cells from human umbilical cord blood and adult peripheral blood to form functional longlasting vessels," Blood, vol. 111, no. 3, pp. 1302-1305, 2008.

[9] T. Takahashi, C. Kalka, H. Masuda et al., "Ischemia- and cytokine-induced mobilization of bone marrow-derived endothelial progenitor cells for neovascularization," Nature Medicine, vol. 5, no. 4, pp. 434-438, 1999.

[10] H. Li, S. Zuo, Z. He et al., "Paracrine factors released by GATA4 overexpressed mesenchymal stem cells increase angiogenesis and cell survival," American Journal of Physiology-Heart and Circulatory Physiology, vol. 299, no. 6, pp. H1772-H1781, 2010.

[11] S.-C. Hung, R. R. Pochampally, S.-C. Chen, S.-C. Hsu, and D. J. Prockop, "Angiogenic effects of human multipotent stromal cell conditioned medium activate the PI3K-Akt pathway in hypoxic endothelial cells to inhibit apoptosis, increase survival, and stimulate angiogenesis," STEM CELLS, vol. 25, no. 9, pp. 23632370, 2007.

[12] I. A. Potapova, G. R. Gaudette, P. R. Brink et al., "Mesenchymal stem cells support migration, extracellular matrix invasion, proliferation, and survival of endothelial cells in vitro," Stem Cells, vol. 25, no. 7, pp. 1761-1768, 2007.

[13] P. S. In't Anker, S. A. Scherjon, C. Kleijburg-van der Keur et al., "Isolation of mesenchymal stem cells of fetal or maternal origin from human placenta," Stem Cells, vol. 22, no. 7, pp. 1338-1345, 2004.

[14] O. K. Lee, T. K. Kuo, W.-M. Chen, K.-D. Lee, S.-L. Hsieh, and T.-H. Chen, "Isolation of multipotent mesenchymal stem cells from umbilical cord blood," Blood, vol. 103, no. 5, pp. 1669-1675, 2004.

[15] C. W. Park, K.-S. Kim, S. Bae et al., "Cytokine secretion profiling of human mesenchymal stem cells by antibody array," International Journal of Stem Cells, vol. 2, no. 1, pp. 59-68, 2009.

[16] G. Li, X.-A. Zhang, H. Wang et al., "Comparative proteomic analysis of mesenchymal stem cells derived from human bone marrow, umbilical cord and placenta: implication in the migration," Advances in Experimental Medicine and Biology, vol. 720, pp. 51-68, 2011.
[17] H. Kupcova Skalnikova, "Proteomic techniques for characterisation of mesenchymal stem cell secretome," Biochimie, vol. 95, no. 12, pp. 2196-2211, 2013.

[18] S. K. Sze, D. P. V. de Kleijn, R. C. Lai et al., "Elucidating the secretion proteome of human embryonic stem cell-derived mesenchymal stem cells," Molecular \& Cellular Proteomics, vol. 6, no. 10, pp. 1680-1689, 2007.

[19] H. Skalnikova, J. Motlik, S. J. Gadher, and H. Kovarova, "Mapping of the secretome of primary isolates of mammalian cells, stem cells and derived cell lines," Proteomics, vol. 11, no. 4, pp. 691-708, 2011.

[20] A. Uccelli, L. Moretta, and V. Pistoia, "Mesenchymal stem cells in health and disease," Nature Reviews Immunology, vol. 8, no. 9, pp. 726-736, 2008.

[21] A. Wilkins, K. Kemp, M. Ginty, K. Hares, E. Mallam, and N. Scolding, "Human bone marrow-derived mesenchymal stem cells secrete brain-derived neurotrophic factor which promotes neuronal survival in vitro," Stem Cell Research, vol. 3, no. 1, pp. 63-70, 2009.

[22] R. A. Boomsma and D. L. Geenen, "Mesenchymal stem cells secrete multiple cytokines that promote angiogenesis and have contrasting effects on chemotaxis and apoptosis," PLOS ONE, vol. 7, no. 4, Article ID e35685, 2012.

[23] A. Burlacu, G. Grigorescu, A.-M. Rosca, M. B. Preda, and M. Simionescu, "Factors secreted by mesenchymal stem cells and endothelial progenitor cells have complementary effects on angiogenesis in vitro," Stem Cells and Development, vol. 22, no. 4, pp. 643-653, 2013.

[24] J. König, G. Weiss, D. Rossi et al., "Placental mesenchymal stromal cells derived from blood vessels or avascular tissues: what is the better choice to support endothelial cell function?" Stem Cells and Development, vol. 24, no. 1, pp. 115-131, 2015.

[25] A. I. Hoch, B. Y. Binder, D. C. Genetos, and J. K. Leach, "Differentiation-dependent secretion of proangiogenic factors by mesenchymal stem cells," PLoS ONE, vol. 7, no. 4, Article ID e35579, 2012.

[26] A. Oskowitz, H. McFerrin, M. Gutschow, M. L. Carter, and R. Pochampally, "Serum-deprived human multipotent mesenchymal stromal cells (MSCs) are highly angiogenic," Stem Cell Research, vol. 6, no. 3, pp. 215-225, 2011.

[27] P. Kuchroo, V. Dave, A. Vijayan, C. Viswanathan, and D. Ghosh, "Paracrine factors secreted by umbilical cord-derived mesenchymal stem cells induce angiogenesis in vitro by a vegfindependent pathway," Stem Cells and Development, vol. 24, no. 4, pp. 437-450, 2015.

[28] V. Severino, A. Farina, and A. Chambery, "Analysis of secreted proteins," Methods in Molecular Biology, vol. 1002, pp. 37-60, 2013.

[29] M. Patarroyo, K. Tryggvason, and I. Virtanen, "Laminin isoforms in tumor invasion, angiogenesis and metastasis," Seminars in Cancer Biology, vol. 12, no. 3, pp. 197-207, 2002.

[30] S. Ali, J. E. Saik, D. J. Gould, M. E. Dickinson, and J. L. West, "Immobilization of cell-adhesive laminin peptides in degradable PEGDA hydrogels influences endothelial cell tubulogenesis," BioResearch Open Access, vol. 2, no. 4, pp. 241-249, 2013.

[31] S.-Y. Chen, J.-S. Lin, and B.-C. Yang, "Modulation of tumor cell stiffness and migration by type IV collagen through direct activation of integrin signaling pathway," Archives of Biochemistry and Biophysics, vol. 555-556, pp. 1-8, 2014.

[32] O. F. Hatipoglu, S. Hirohata, M. Z. Cilkek et al., "ADAMTS1 is a unique hypoxic early response gene expressed by endothelial 
cells," The Journal of Biological Chemistry, vol. 284, no. 24, pp. 16325-16333, 2009.

[33] Y.-H. Yang, H. Zhou, N. O. Binmadi, P. Proia, and J. R. Basile, "Plexin-B1 activates NF-kappaB and IL-8 to promote a proangiogenic response in endothelial cells," PLoS ONE, vol. 6, no. 10, Article ID e25826, 2011.

[34] Y. Ikeda, K.-I. Aihara, S. Yoshida et al., "Heparin cofactor II, a serine protease inhibitor, promotes angiogenesis via activation of the AMP-activated protein kinase-endothelial nitric-oxide synthase signaling pathway," The Journal of Biological Chemistry, vol. 287, no. 41, pp. 34256-34263, 2012.

[35] N. Awasthi, M. A. Schwarz, V. Verma, C. Cappiello, and R. E. Schwarz, "Endothelial monocyte activating polypeptide II interferes with VEGF-induced proangiogenic signaling," Laboratory Investigation, vol. 89, no. 1, pp. 38-46, 2009.

[36] Y. Hou, P. A. Plett, D. A. Ingram et al., "Endothelial-monocyteactivating polypeptide II induces migration of endothelial progenitor cells via the chemokine receptor CXCR3," Experimental Hematology, vol. 34, no. 8, pp. 1125-1132, 2006.

[37] P. Danieli, G. Malpasso, M. C. Ciuffreda et al., "Conditioned medium from human amniotic mesenchymal stromal cells limits infarct size and enhances angiogenesis," Stem Cells Translational Medicine, vol. 4, no. 5, pp. 448-458, 2015. 

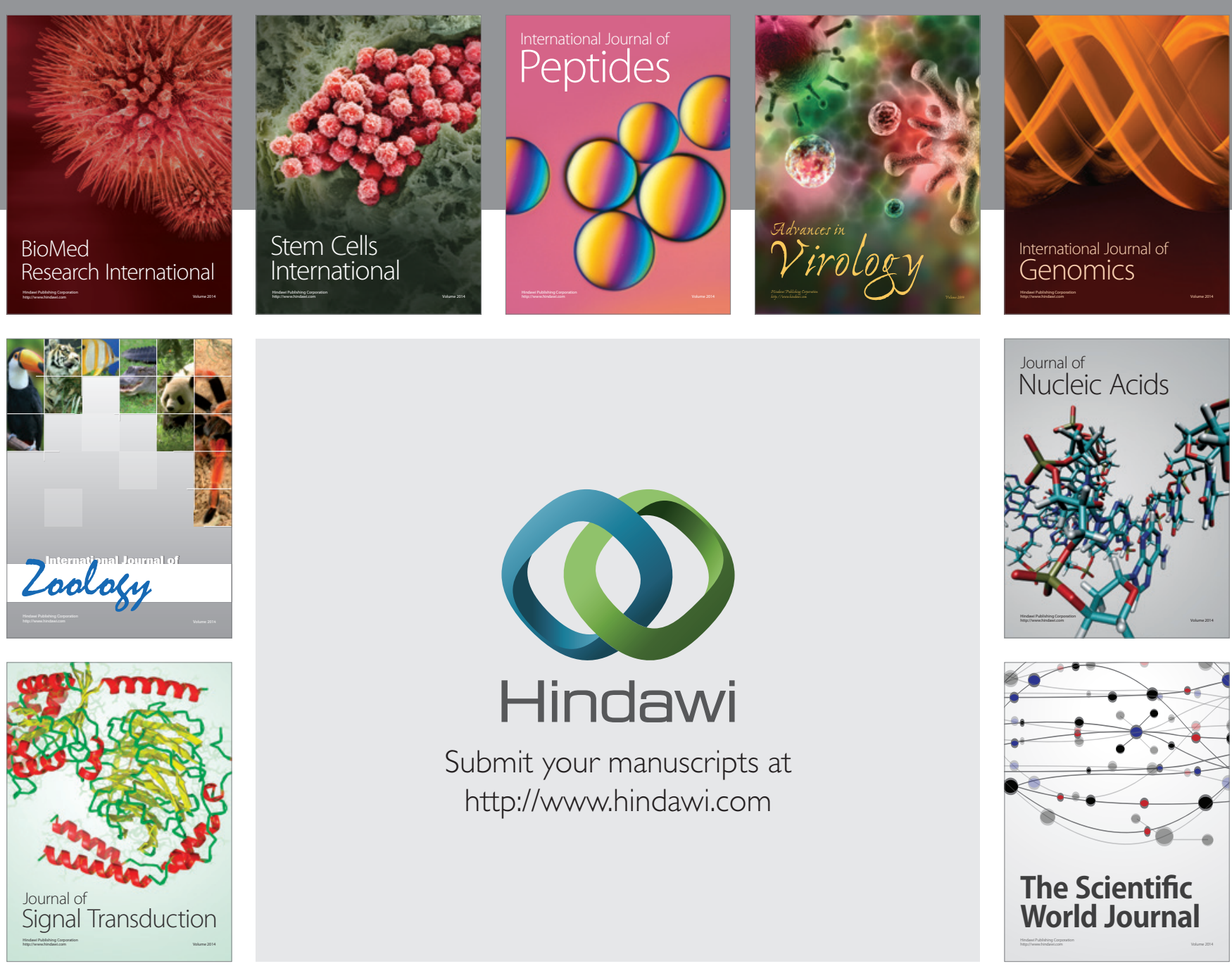

Submit your manuscripts at

http://www.hindawi.com
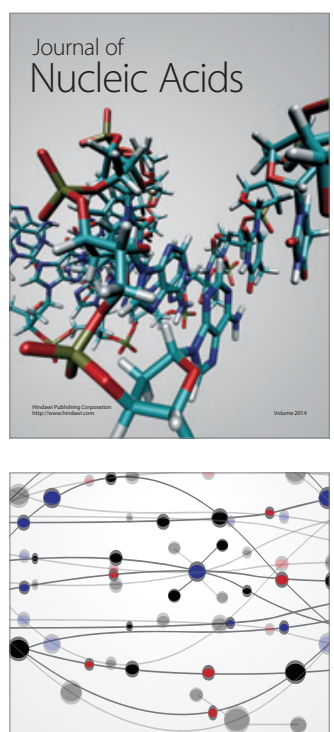

The Scientific World Journal
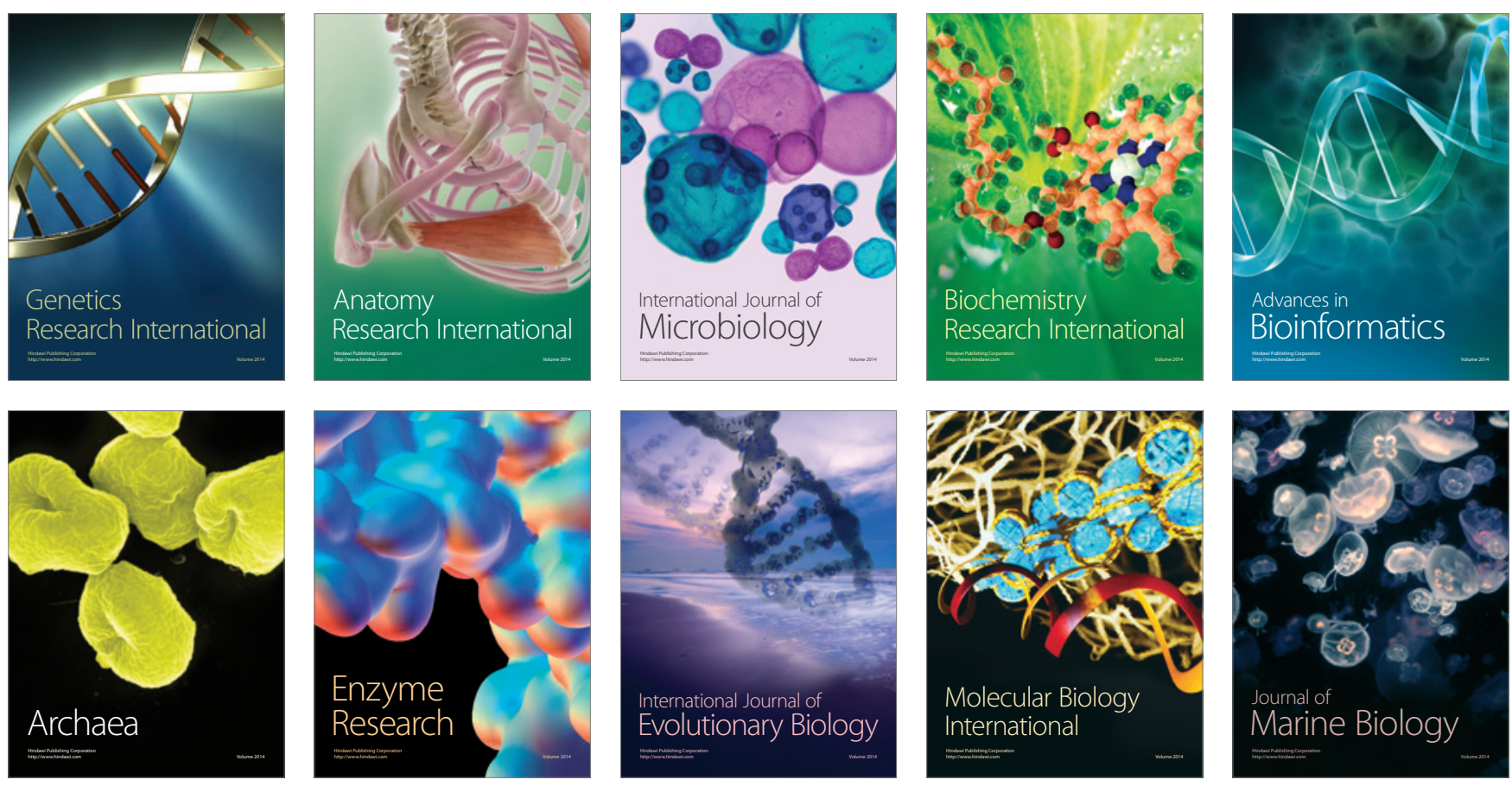